Dam, but afterwards officially designated the Hoover Dam, across the Colorado River in Black Canyon, which forms the boundary between the States of Arizona and Nevada, at a point about twenty-five miles south-east of Las Vegas, Nevada, marks the attainment of an advanced stage in the execution of the notable Boulder Canyon Project, the Act for which was approved by the United States President in December 1928. The project in its entirety comprises not only the construction of a dam and the formation of an artificial lake, respectively the highest and the most capacious of their kind in the world, but also other incidental works involving an expenditure estimated at the time at 165 million dollars. The probable outlay is now given as 385 million dollars. The dam has a maximum height of about $730 \mathrm{ft}$., an extreme length of $1,180 \mathrm{ft}$., a crest width of $45 \mathrm{ft}$. and a bottom thickness of $650 \mathrm{ft}$. It contains about $4 \frac{1}{2}$ million cubic yards of concrete, and will be the retaining wall of a reservoir having a length of 115 miles and a total cubic capacity of $30,500,000$ acre-feet. It is designed to impound the flood water of the Colorado River for use in irrigation, and will serve to regulate the flow of that stream so as to improve its navigability, and protect the adjacent valleys from overflow, water shortage and silt accumulation. Irrigation and protection from inundation of valuable farm lands in Southern California are the primary and essential objects of the undertaking, but hydraulic turbines of exceptional calibre are also being installed to enable electric power to be generated, the revenues from which will fully recoup the outlay on the entire scheme, which, including a main irrigation canal, 80 miles in length, with an extension 130 miles long to adjacent valleys, is among the most remarkable instances of engineering enterprise in modern times.

\section{Anti-Noise Exhibition}

The Prime Minister will open on May 31 at the Science Museum, South Kensington, an Anti-Noise Exhibition which is being arranged through the Anti-Noise League. The Exhibition will remain open throughout the month of June and probably conclude with a congress during the last week. The chairman of the League, Lord Horder, broadcast on the subject of the Exhibition on January 20. It is proposed that the Exhibition shall present a comprehensive survey of the whole problem of noise in its many aspects. The practical co-operation of a number of institutions and public bodies has already been obtained, including the Ministry of Transport, the Air Ministry, the National Physical Laboratory, the Post Office Research Laboratories, the British Broadcasting Corporation, the Industrial Health Research Board, and a number of industrial research laboratories. Dr. G. W. C. Kaye, of the National Physical Laboratory, is chairman of the Research and Development Section of the Exhibition, Prof. Cave-Browne-Cave, of the Transport and Machinery Section, Mr. Hope Bagenal, of the Building Section, and Sir Henry Richards, of the Organising Committee. The Science Museum has placed generous accommodation, including a cinema theatre, at the disposal of the Exhibition and it is hoped to display many interesting exhibits of noise abatement appliances. A small silent house is to be erected which will incorporate the latest architectural and building designs and materials for sound proofing and sound absorption. There will be a number of demonstrations, including silenced pneumatic drills, motor-cycles, typewriters, vacuum cleaners, electric motors, circular saws and so on. The latest devices for the measurement, analysis and filtering of noise will be shown, the psychological aspects of noise will receive attention, and experiments on the value of ear defenders, the masking of noises, the effect of noise on loudness of speaking and the use of noise-level alarms will claim the interest of most people. The effect of noise on output in industry will be illustrated by the results of recent investigations.

\section{The Microscope and the Metal Industries}

Dr. C. H. Desch delivered a Research and Development Lecture under the auspices of the Royal Institution and the British Science Guild on February 6 , taking as his subject "The Microscope and the Metal Industry". Although a careful drawing of a metallic object (the edge of a razor) was published by Robert Hooke in 1665 , it was two hundred years before any further use was made of the microscope in the study of metals. H. C. Sorby, a Sheffield amateur, began in 1854 to apply the microscope to polished and etched surfaces of steel and succeeded in identifying correctly a number of separate constituents in the varieties of steel and cast iron avail. able to him. It was twenty years before these results attracted any attention, but from that time onwards, the microscope has become an indispensable tool in the metallurgical industry. Specimens of metals are ground and polished, care being taken to avoid distortion, and are then etched by means of a suitable reagent which will distinguish between the various constituents. All metals and alloys are built up of crystals, and the relative sizes of the component crystals frequently determine the properties of the mass. With this object in view, systematic measurements of crystal size are made as metals are passing through the processes of manufacture. The reading of a micro-section may be compared with the reading of a map, which conveys the more information the greater the experience of the person using it. A further important application of the microscope is in the study of failures. The fracture of crankshafts and other moving parts by fatigue, the cracking of boiler plates and superheater tubes, the breakage of wire ropes, and the cracking of severely cold-worked sheets, are typical examples of occurrences on which the microscope is capable of throwing light by indicating the nature of the processes concerned in the failure, and thereby giving a clue as to their origin. The microscope has now become an essential part of the equipment of every works dealing with the production of metal, and also with the transformation of metals into useful products on a large scale. 